\title{
ACARDIAC TWIN
}

S. Vinayachandran ${ }^{1}$, Jyothi Chandran², Bindu Vijayakumar ${ }^{3}, \mathrm{~N}^{2}$ Umadevi $^{4}$

\section{HOW TO CITE THIS ARTICLE:}

S. Vinayachandran, Jyothi Chandran, Bindu Vijayakumar, N Umadevi. "Acardiac Twin”. Journal of Evolution of Medical and Dental Sciences 2014; Vol. 3, Issue 02, January 13; Page: 356-358,

DOI:10.14260/jemds/2014/1833

INTRODUCTION: Acardiac twin is a very rare complication occurring in monozygotic twins in which one fetus develops normally (pump twin) and the other (recipient twin) demonstrate cardiac non development and other anomalies. This may represent an extreme form of TTTS, also referred to as TRAP sequence.1,2,3

\section{Incidence:}

$1 \%$ of monozygotic twins $1,2,3$

1 in 35000 pregnancies ${ }^{1,2,3}$

CASE REPORT: A 27 year old G2 P1 L1 patient with previous caesarian section presented at 22 weeks gestation in our antenatal clinic with the following findings.

BP 110/80 mm Hg, pulse 80/min, no edema

Systemic examination -NAD

P/A -uterus 24 weeks, fetal parts +, fetal heart sounds +, liquor normal, no scar tenderness

\section{USG findings:}

Twin A -cephalic presentation, normal fetal anatomy, biometry showed a gestational age of 22 weeks +1 week

Twin B -an amorphous mass stuck to uterine wall showing no cardiac activity. Part of spine and long bones were seen. This twin was motionless.

Placenta -single posterior, Grade I

Liquor normal in amount. Sac monoamniotic

Diagnosis -MAMC, twin gestation with one normal fetus and other acardiac twin with gestational age of 22 weeks +1 week

Management: Patient was counselled and was advised of the prognosis, risk of preterm labour, need for repeated ultrasound evaluation. She opted for conservative management.

Presented at 29 weeks 3 days gestation with $1_{\text {st }}$ acardiac stuck twin, $2^{\text {nd }}$ twin - hydrops fetalis -IUD.

She had a VBAC

Findings: acardiac twin, sex not identifiable, weight $260 \mathrm{G}$ with lower limb -like structure and an amorphous mass. 2nd twin male IUD -MSB 490 G. placenta monochorionic and mono amniotic 


\section{CASE REPORT}

DISCUSSION: Acaridac twin -First described in 16 th century by Benedetti as Chorioangiophagus parasiticum. New nomenclature is TRAP sequence ${ }^{1}$. Pathogenesis remains controversial. Evidence suggest arterio -arterial anastomosis in the placenta and perfusion of the anomalous twin by reversal of flow through umbilical arteries and iliac arteries resulting in maldevelopment ${ }_{3,4}$. Healthy twin later succumbs to high output failure, hydrops fetalis and IUD. It has got a perinatal mortality of $50 \%$.

Types of acardiac twin

Acardiac acephalus -no cephalic structures present.

Acardiac anceps -some cranial structures and neuronal elements present

Acardiac acormus -cephalic structure present. No truncal structures

Acardiac amorphous -no demonstrable cephalic or truncal structures present 2

\section{Management:}

Needs serial ultrasound \& doppler evaluation to assess the growth rate and vascular status of normal twin. Obstruction of blood flow to the acardiac twin is the key. It can be achieved by various means like thrombogenic coil in umbilical artery of acardiac twin, endoscopic umbilical cord ligation, endoscopic laser coagulation of A -A anastomosis, FIGS (fetal image guided surgery) using radiofrequency ablation ${ }_{1,3,5}$, serial amnioreduction and expectant management as described by Sullivan in 2003. Patient should be given counselling regarding the prognosis according to TWR ie-weight of acardiac twin / weight of normal twin. If it is $>70 \%$, prognosis is bad

CONCLUSION: Ours was a case of MCMA acardiac amorphous twin. Management of TRAP sequence include serial ultrasound to assess growth rate and cardiovascular status of normal twin and occlusion of blood flow to the recipient twin.

Future is for FIGS with thermocoagulation.

\section{REFERENCES:}

1. Pandey Kiran, Arya Sangeetha et al, Journal of Obs \& Gyn. Of India Vol.60, Jan Feb 2010 pg $75-76$.

2. Fernando Arias, Practical guide to high risk pregnancy and delivery 3rd ed 2008 pg 307.

3. Chandasenanont A et al Acardiac twin J Med Aso Thai 2005; 88.1721.

4. Dashe J S Fernandez, TRAP sequence Am J OBG 2001;185:135-9.

5. Lemery D J et al OBG 1994;4:399-401.

6. Tsao K, Feldstein VA et al Am J OBG 2002;187; 635 -40. 


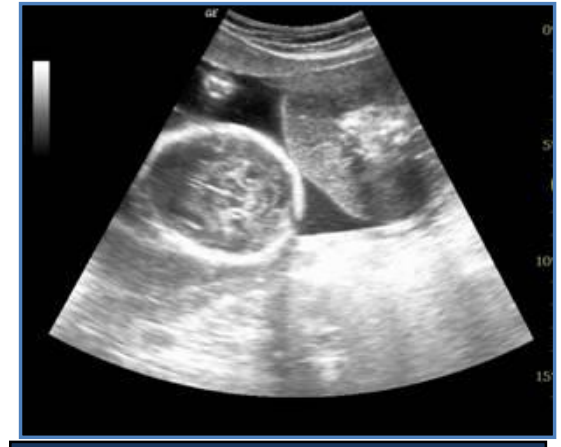

USG -Acardiac twin \&Normal fetal head

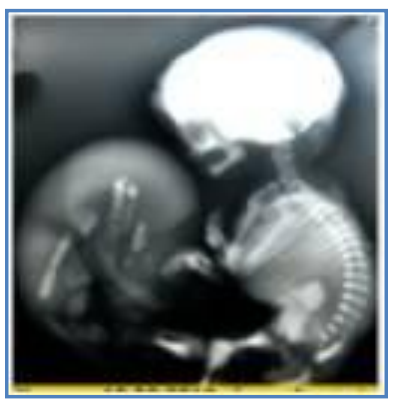

Radiograph Acardiac twin \& normal fetus

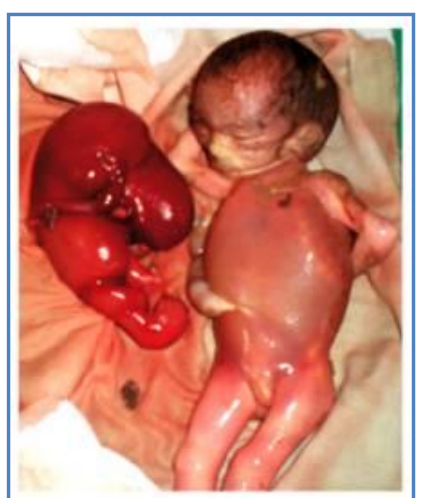

Expelled normal fetus and Acardiac twin

\section{AUTHORS:}

1. S. Vinayachandran

2. Jyothi Chandran

3. Bindu Vijayakumar

4. N Umadevi

\section{PARTICULARS OF CONTRIBUTORS:}

1. Additional Professor, Department of Obstetrics and Gynaecology, Institute of Maternal \& Child Health, Government Medical College, Calicut, Kerala, India.

2. Associate Professor, Department of Obstetrics and Gynaecology, Institute of Maternal \& Child Health, Government Medical College, Calicut, Kerala, India.

3. Assistant Professor, Department of Obstetrics and Gynaecology, Institute of Maternal \& Child Health, Government Medical College, Calicut, Kerala, India.
4. Professor, Department of Obstetrics and Gynaecology, Institute of Maternal \& Child Health, Government Medical College, Calicut, Kerala, India.

\section{NAME ADDRESS EMAIL ID OF THE CORRESPONDING AUTHOR:}

Dr. S. Vinayachandran, Additional Professor of O \& G, IMCH, Govt. Medical College, Calicut - 673 008, Kerala, India. Email-drvinayans@gmail.com

Date of Submission: 15/12/2013. Date of Peer Review: 16/12/2013. Date of Acceptance: 27/12/2013. Date of Publishing: 09/01/2014 